\title{
Café com Especialistas: A Importância do Diálogo entre a Comunidade Discente e os Egressos de um Curso de Engenharia
}

\author{
DOI: 10.37702/2175-957X.COBENGE.2021.3570
}

Danton Buticosihz Müller - dantonbm@outlook.com

Universidade Federal de Uberlândia

Rua Desembargador Augusto Botelho 1000

29101-110 - Vila Velha - ES

Felipe Fernandes Cunha - felipefc.uberlandia@gmail.com

Universidade Federal de Uberlândia

Rua Leandro José de Oliveira 404

38408-632 - Uberlândia - MG

Matheus Lopes Silva - matheuslopesilva@gmail.com

Universidade Federal de Uberlândia

Rua dos Antúrios 479

38412-100 - Uberlândia - MG

Ana Marta Souza - anamartaengenharia@gmail.com

Universidade Federal de Uberlândia

Rua Jangadeiros 201

38412-016 - Uberlândia - MG

Resumo: No presente trabalho será apresentado o desenvolvimento do evento "Café com Especialista" promovido pelo Programa de Educação Tutorial da Engenharia Mecânica da Faculdade de Engenharia Mecânica (PETMEC) da Universidade Federal de Uberlândia (FEMEC/UFU), no qual objetivou aproximar os discentes dos cursos de graduação com especialistas atuantes no mercado de trabalho. Para isso, realizaram-se cinco edições temáticas do evento, em que foram convidados diversos egressos da própria Universidade para exporem as respectivas experiências -profissionais. Ainda, em virtude da pandemia de COVID-19, esta atividade foi realizada de forma remota por meio de transmissões ao vivo hospedadas no canal do PETMEC no YouTube, as quais se mantiveram disponíveis para acesso em formatos de vídeo posteriormente ao evento. Para 
avaliar o alcance, a execução e cumprimento dos objetivos do evento, analisou-se o número de visualizações das edições do evento, ultrapassando 2000 visualizações no total, e as respostas de avaliação realizadas em formulário pelos participantes. Com isso, obteve-se que acima de $98 \%$ dos participantes acharam a organização boa ou excelente e 95\% tiveram as expectativas atendidas, o que comprovou a excelência de organização. Ainda, realizou-se uma análise qualitativa, por meio de comentários dos participantes, sobre o objetivo do evento de apresentação e integração com profissionais egressos. Diante desta análise, pode-se concluir que o evento atingiu o objetivo proposto, com vista que os participantes afirmaram sobre a contribuição do evento nas respectivas formações, apresentando ampla perspectiva do ramo de atividades trabalhistas e diversos conselhos a fim de complementar a formação acadêmica.

Palavras-chave: Mercado de Trabalho, Extensão Universitária, PET, Implementação das Novas DCNs. 


\section{(C) COBENGE \\ 28 a 30 de SETEMBRO \\ Café com Especialistas: A Importância do Diálogo entre a Comunidade Discente e os Egressos de um Curso de Engenharia}

\section{INTRODUÇÃO}

As Novas Diretrizes Curriculares Nacionais (DCNs) do curso de engenharia estabelecem a maior aproximação entre o mercado de trabalho e os cursos de graduação. Uma dessas ações apontadas é o acompanhamento de egressos do curso, como visto em: "Devem ser definidas as ações de acompanhamento dos egressos, visando à retroalimentação do curso" (ABMES, 2019). Além disso, as diretrizes recomendam a promoção de atividades com a participação de profissionais que visam debater a evolução constante da engenharia e que ajudem a definir o perfil do egresso.

Como visto em estudo de Araújo; Sarriera (2004), são frequentes os casos de jovens que tem suas expectativas frustradas quanto a inserção no mercado de trabalho. Assim sendo, os mesmos autores abordam que a reformulação dos planos de vida é algo a ser encarado por esses jovens, que devem, então, buscar por novos caminhos. Essas novas trajetórias podem incluir o aceite de um emprego em uma área diferente da formação, a busca por oportunidades profissionais em outros estados ou países, a opção por uma pósgraduação ou até mesmo um novo curso de graduação. Neste aspecto, os autores destacam que há uma carência de informações aos jovens e a quem lida com eles que deem suporte a transição universidade-mercado de trabalho.

Sabendo que a realidade de alguns discentes não foge dos casos acima, o Programa de Educação Tutorial da Faculdade de Engenharia Mecânica (PETMEC) da Universidade Federal de Uberlândia (UFU) planejou uma atividade que promovesse uma troca de experiências entre egressos dos cursos de graduação em Engenharia Mecânica, Mecatrônica e Aeronáutica com a comunidade discente atual. Ressalta-se aqui que, desde o planejamento da primeira edição, o propósito da atividade era de convidar egressos em diferentes carreiras.

Nesse sentido, segundo Magalhães; Teixeira (2013), percepções positivas quanto ao mercado de trabalho podem afetar os níveis de motivação e crenças de autoeficácia nos futuros egressos que pretendem começar sua carreia profissional. Reforça-se também que muitos dos discentes participantes viram que seus sofrimentos e angústias foram similares àqueles enfrentados por egressos que hoje possuem uma boa carreira.

Diante desse contexto, o principal objetivo do presente trabalho é descrever e analisar, quantitativa e qualitativamente, a promoção de uma atividade que visou a troca de experiências entre egressos e discentes da Faculdade de Engenharia Mecânica da UFU, promovida pelo PETMEC.

\section{METODOLOGIA}

Em sua concepção original, esperava-se uma série de encontros presenciais descontraídos, que permitisse aos egressos compartilharem suas histórias de vida, ampliando o horizonte de oportunidades dos estudantes e mostrar que, em alguns casos, o fracasso pode ser um grande motivador para uma carreira de sucesso. A fim de promover esse evento como um bate-papo agradável e tranquilo, a atividade recebeu o nome de "Café com Especialista".

Com a suspensão das atividades presenciais em razão da pandemia de COVID-19, o evento foi adaptado para o formato virtual, sendo a primeira atividade do grupo PETMEC a acontecer de forma remota. Se por um lado perdeu-se a conexão física, por outro pode- 
se dizer que realizar o evento da forma virtual permitiu ao grupo trazer convidados que se formaram na UFU, mas que não mais habitam em Uberlândia.

O evento contou com cinco edições ao total, descritas na Tabela 1 e, apesar das diferentes temáticas abordadas, seus planejamentos foram similares e podem ser explicados como segue. Em um primeiro aspecto, definia-se qual a temática a ser abordada, a qual era escolhida com base nas sugestões advindas da comunidade discente. Os participantes eram convidados com base na sugestão de professores e dos próprios petianos. Tendo concluído essa etapa, a divulgação começava por meio de postagens em redes sociais, envio de e-mails, textos e mensagens.

Tabela 1 - Edições do evento "Café com Especialista".

\begin{tabular}{c|c}
\hline Tema & Descrição \\
\hline Mercado de Trabalho & Engenheiros que atuam em uma empresa \\
\hline Engenheiras & Atuação de mulheres na engenharia \\
\hline Edição Internacional & $\begin{array}{c}\text { Engenheiros e docentes em engenharia que } \\
\text { atuam fora do país }\end{array}$ \\
\hline Empreendedores & $\begin{array}{c}\text { Engenheiros que abriram o próprio negócio } \\
\text { Outros Rumos }\end{array}$ \\
\hline $\begin{array}{c}\text { Engenheiros formados, mas que não atuam } \\
\text { na área }\end{array}$
\end{tabular}

Fonte: Dados dos autores.

O evento foi transmitido ao vivo no canal do PETMEC no YouTube, que permitia aos participantes interagirem por chat com os convidados. O evento contava com um roteiro de perguntas iniciais, as quais eram repassadas aos egressos convidados pelo petiano apresentador. Ao decorrer do evento as dúvidas dos participantes eram coletadas e repassadas para serem respondidas ainda durante o evento.

A avaliação do evento ocorreu por meio de um formulário hospedado em uma plataforma online e estava atrelada à emissão de certificado, levando a um número de respostas significativos. Ademais, uma avaliação interna também foi realizada a fim de se saber quais aspectos organizacionais poderiam ser melhorados.

\section{$3 \quad$ RESULTADOS E DISCUSSÕES}

Para validar se o evento atingiu os objetivos propostos, avaliou-se a quantidade de visualizações de cada edição, apresentado na Tabela 2, e utilizou-se de um formulário eletrônico, o qual possuía diversas indagações aos participantes, referentes à divulgação, organização, satisfação e informações pessoais. Estes resultados estão apresentados em diversos gráficos nas Figuras 1, 2 e 3. Ressalta-se que o formulário de avaliação só esteve disponível durante os instantes finais do evento ao vivo. No entanto, o acesso a gravação foi disponibilizado após o evento, permitindo que mais pessoas fossem beneficiadas por ele.

Tabela 2 - Visualização dos vídeos até abril de 2021.

\begin{tabular}{c|c}
\hline Edição & Visualizações \\
\hline Mercado de Trabalho de Engenharia & 559 \\
\hline
\end{tabular}




\begin{tabular}{c|c}
\hline Engenharias & 489 \\
\hline Edição Internacional - Docentes & 324 \\
\hline Edição Internacional - Engenheiros & 453 \\
\hline Empreendedores & 230 \\
\hline Outros Rumos & 145 \\
\hline Total & 2200
\end{tabular}

Fonte: Dados dos autores.

A partir da Tabela 2 percebe-se que o evento obteve o engajamento esperado, inicialmente estimado em 40 participantes por edição. Ainda, vale ressaltar que todas as edições ficaram disponíveis no canal do YouTube do PETMEC para visualização posterior. Ademais, percebeu-se uma queda de visualizações em especial nas duas últimas edições, o que se acredita estar ligado ao início das aulas remotas na Universidade, o que reduziu consideravelmente o tempo disponível dos discentes para acompanhar diversos eventos como anteriormente.

Indagou-se sobre a organização do evento, de modo que os participantes indicassem a satisfação deles neste quesito. Esses resultados estão apresentados na Figura 2.

Figura 1 - Resultados da avaliação da organização.

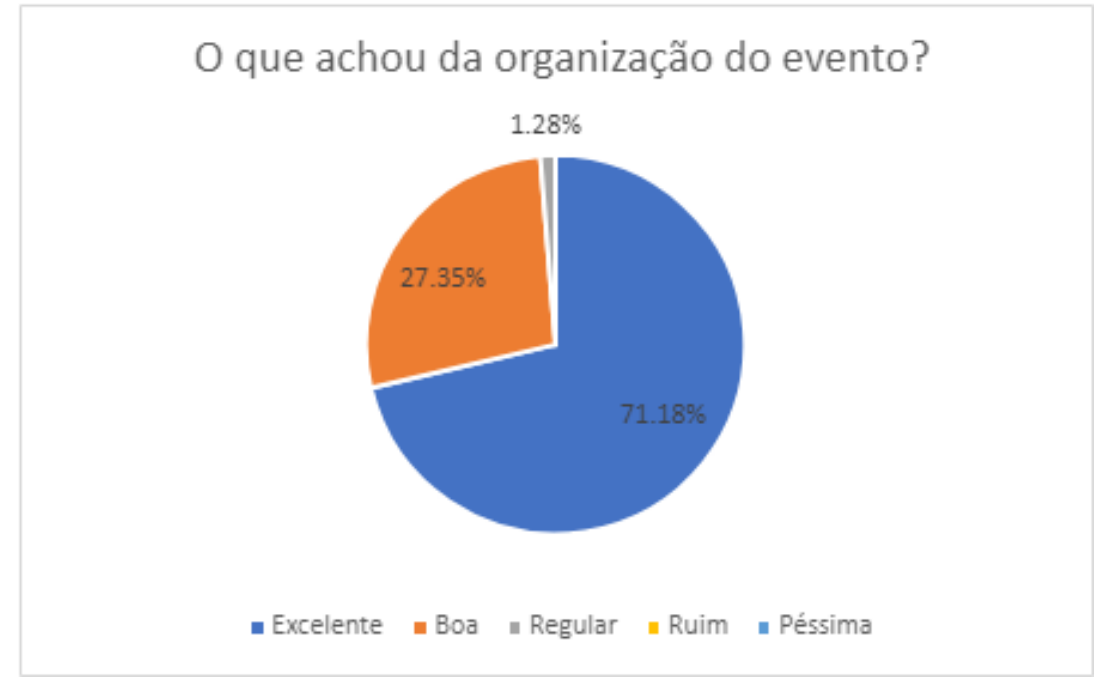

Fonte: Dados dos autores.

Com isso, conclui-se que a organização do evento durante todas as edições foi bem avaliada, de forma que 98,72 \% dos participantes indicaram que a organização foi boa ou excelente.

Os participantes também foram questionados se o evento atendeu as expectativas individuais, em que os resultados obtidos estão mostrados na Figura 3.

Este resultado aponta que $95,67 \%$ dos participantes avaliaram com notas 4 ou 5 se as expectativas foram atendidas. Isto indica, novamente, o sucesso de realização do evento, ao mostrar que as expectativas da maioria dos participantes foram atendidas ou superadas. 
Figura 2 - Resultados da avaliação quanto à expectativa dos participantes.

O evento atendeu às suas expectativas?

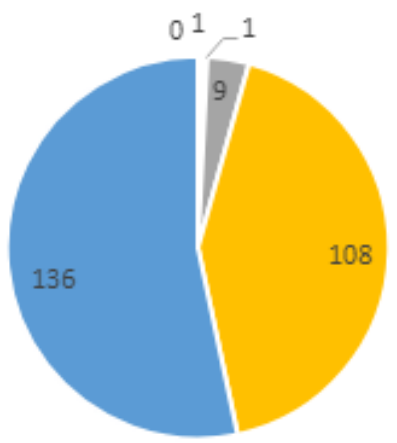

- Nota 1 - Nota 2 |n Nota 3 | Nota 4 - Nota 5 - Nota 0

Fonte: Dados dos autores.

Nessa perspectiva, pode-se também analisar qualitativamente os comentários obtidos por meio do formulário avaliativo. Alguns respondentes relataram que a identificação com os relatos dos convidados, que muitas vezes passaram por situações semelhantes a eles, serve como motivação para a continuidade nos estudos, como visto em:

"O que mais gostei foi a franqueza delas [convidadas] em relação a suas experiências. Que não é o aluno que tira as melhores notas que consegue um emprego bacana depois, e frustrações como lidar com uma reprovação ou professores ou preconceitos são parte do dia a dia e você tem que ter forças para lidar com isso."

"As experiências de vida de cada palestrante, acrescenta muito na vida e motivação de um aluno."

Os comentários feitos ainda revelam que atividade permitiu aos atuais estudantes compreenderam melhor algumas dúvidas quanto às atividades acadêmicas, como a participação em um intercâmbio ou projeto de pesquisa, como observado em:

"Foi muito esclarecedor, principalmente para nós que entramos agora. Dúvidas são assustadoras e ouvir de quem tem experiência no assunto ajuda muito."

"O evento me ajudou a sanar algumas dúvidas a respeito de Intercâmbio."

Ainda nesse sentido, não se pode esquecer da realidade da pandemia que exigiu a parada repentina das aulas presenciais. Muitos relatos apontam que as atividades do PET, incluindo o "Café com Especialista" permitiram o reencontro com colegas de curso, servindo como um alento para esse período. Reforça-se aqui também que alguns participantes dessa atividade eram ingressantes e ainda não tinham tido a oportunidade de terem aulas presenciais, como visto em:

"O café com especialista me motivou muito com o curso, principalmente os primeiros, pois havia acabado de ingressar no curso no começo da pandemia." 
"Fiquei muito insegura no começo por não estar tendo aulas, pensei em trocar de curso. Contudo, ao ouvir relatos dos egressos do curso, fiquei mais motivada."

Outro grupo de comentários diz respeito à inserção no mercado de trabalho. Os respondentes relatam que os convidados permitiram entender melhor o que as empresas esperam de um engenheiro recém-formado. Isso pode ser observado em:

"O que mais me agradou foi importância de gestão de pessoas, comunicação e criatividade no mercado de trabalho. Os depoimentos das meninas também é um gatilho imenso para nós graduandas."

"É bom ver a realidade dos processos seletivos, em que provavelmente não será aprovado no primeiro, mas que você crescerá profissionalmente com o tempo no mercado"

Não se pode resumir os benefícios dessa atividade aos discentes. Diversos ex-alunos relatam uma percepção positiva destes eventos, mostrando como eles permitem a criação de uma rede de contatos e conexões, que pode vir a ser útil aos discentes e ao já formados, ao passo que cria uma relação entre essas duas comunidades. Isso pode ser visto em:

"Vi com muita satisfação que vocês estão promovendo lives com alunos e ex-alunos, ajudando a comunidade de engenharia com referências e troca de informações. Acompanhei parcialmente a live de ontem e achei bem bacana a interação."

Isso inclusive levou a vários deles se colocarem à disposição do grupo para a participação em algum outro evento futuro, como aqui:

"Estou à disposição caso vocês tenham interesse em fazer uma live comigo (ou qualquer outra atividade), para que os alunos possam fazer perguntas e tirar dúvidas com um ex-aluno que já tenha uma boa experiência no mercado."

Ainda sobre a participação de egressos, ao buscar possíveis convidados ao evento, o grupo PET começou a montar um banco de dados de contatos de ex-alunos. Os primeiros nomes surgiram por recém-formados, que ainda tinham conexão com colegas universitários, e por professores que passaram informações de outros formados. A fim de aumentar esse banco de dados, o grupo também criou um formulário online divulgado por e-mail, tendo mais de 100 preenchimentos de egressos.

Pode-se dizer que esse formulário vai de encontro ao trabalho a ser desenvolvidos pelas coordenações dos cursos no que tange sobre o acompanhamento de egressos estipulado pelas novas DCNs.

A Figura 3 representa a distribuição do público por período na faculdade. Esta distribuição é de extrema relevância neste evento, visto que é desejado saber o público que se atingiu e, assim, melhorar a divulgação para períodos que houve menor participação, além de buscar possíveis motivações para o menor engajamento em determinados períodos. 
Figura 3 - Distribuição de período dos participantes.

\section{Qual o seu período?}

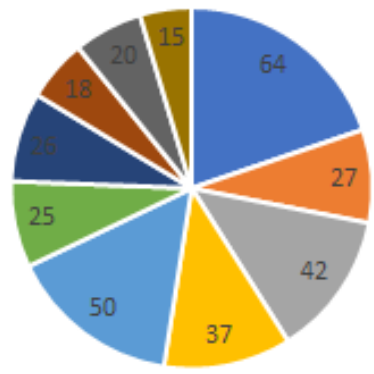

| $19=29$ | $39=49$ || 59 || 69 | 79 | 89 | 99 | 109

Fonte: Dados dos autores.

Pode-se perceber que quase $50 \%$ dos participantes estavam entre os quatro primeiros períodos do curso. Então, durante todas as edições, buscou-se reforçar o máximo possível a divulgação para maiores períodos, de maneira a aumentar esse público.

Por fim, analisou-se também os cursos de graduação que participaram das diversas edições do evento, os quais foram: Administração; Agronomia; Arquitetura; Biologia; Ciências Contábeis; Economia; Engenharia Aeronáutica; Engenharia Agronômica; Engenharia de Alimentos; Engenharia Ambiental e Sanitária; Engenharia da Computação; Engenharia Elétrica; Engenharia Eletrônica e de Telecomunicações; Engenharia Mecânica; Engenharia Mecatrônica; Engenharia Química; Matemática.

Percebe-se que o evento atingiu uma enorme gama de cursos ao longo das variadas edições, de modo que a variedade dos temas se mostrou interessante inclusive para públicos externos à engenharia. Acredita-se, que este dado demonstra o interesse dos estudantes com relação ao contato profissionais atuantes no Mercado de Trabalho, e ou mesmo, com egressos da mesma Instituição.

\section{CONCLUSÃO}

A partir dos dados apresentados, é possível concluir que o evento obteve excelência de organização e execução. Além disso, o evento também atingiu o objetivo proposto com relação à troca de experiências com a comunidade externa, de modo que as expectativas dos participantes sobre o evento foram majoritariamente atendidas ou superadas e se contou com participantes bem avaliados, que repassaram efetivamente suas experiências no mercado de trabalho.

Ainda nesse sentido, pode-se dizer que o evento permitiu aos envolvidos o maior contato com o mercado de trabalho através das experiências profissionais transmitidas pelos convidados, egressos da própria universidade. Além disso, percebe-se que o evento proporcionou a resolução de diversas dúvidas dos participantes em temas de extrema relevância como a importância e participação em programas extracurriculares durante a formação acadêmica, inserção e atuação como profissional da área.

Com isso, acredita-se que o evento tenha contribuído ativamente com a formação e ampliação da rede de contatos dos discentes, além de motivá-los em relação ao curso escolhido e ao melhor aproveitamento da respectiva graduação. 


\section{REFERÊNCIAS}

ABMES. RESOLUÇÃO No 2, DE 24 DE ABRIL DE 2019, 2019. Disponível em: $<$ www.abmes.org.br>. Acesso em 23 de abirl de 2021.

ARAÚJO, J. S.; SARRIERA, J. C. Redirecionamento da Carreira Profissional: uma Análise Compreensiva. In: SARRIERA, J. C.; ROCHA, K. B.; PIZZINATO, A. (Eds.). . Desafio do Mundo do Trabalho: Orientação, Inserção e Mudanças. Porto Algegre: EDPUCRS, 2004. p. pp.135-57.

MAGALHÂES, M. DE O.; TEIXEIRA, M. A. P. Antecedentes de comportamentos de busca de emprego na transição da universidade para o mercado de trabalho. Psicologia: Teoria e Pesquisa, v. 29, n. 4, p. 411-419, dez. 2013.

Abstract: The present work will present the development of the event "Café com Especialista" promoted by the Tutorial Education Program of the Faculty of Mechanical Engineering (PETMEC), linked to the Federal University of Uberlândia (FEMEC / UFU), in which it aimed to bring undergraduate students closer to the job market. For this, five thematic editions of the event were realized, in which several graduates were invited to expose their respective experiences in the labor market. Also, due to the COVID-19 pandemic, this activity was carried out remotely through live broadcasts hosted on the PETMEC channel, on YouTube, which remained available for access in video formats after the event. In order to assess the scope, execution and fulfillment of the event's objectives, the number of views of the event editions was analyzed, exceeding 2000 views in total, and the assessment responses made on form by the participants. With that, it was obtained that over $98 \%$ of the participants thought the organization was good or excellent, $95 \%$ had their expectations met, which confirm the excellence in organization. Moreover, a qualitative analysis was made, by participants comments, to verify if the event achieved the objective of presentation and integration with the labor market. That analysis confirmed that the event achieved the proposed objective, with many comments that affirmed about the contribution of the event in their professional qualification, presenting a wide perspective of labor market and several advices about how to complement their academic education.

Keywords: labor market, university extension, PET, implementation of new DCNs. 